\title{
Remodeling of membrane lipids in gills of adult hard clam Mercenaria mercenaria during declining temperature
}

\author{
Geneviève J. Parent ${ }^{1}$, Fabrice Pernet ${ }^{2,3, *}$, Réjean Tremblay $^{1}$, Jean-Marie Sévigny ${ }^{4}$, \\ Marc Ouellette ${ }^{5}$
}

${ }^{1}$ Institut des sciences de la mer, Université du Québec à Rimouski, 310 allée des Ursulines, Rimouski, Quebec G5L 3A1, Canada

${ }^{2}$ Institut de Recherche sur les Zones Côtières, 232-B rue de l'Église, Shippagan, New Brunswick E8S 1J2, Canada

${ }^{3}$ IFREMER, Laboratoire environnement Ressources, Avenue Jean Monet, BP 171, 34203 Sète Cedex, France

${ }^{4}$ Institut Maurice Lamontagne, Pêches \& Océans Canada, Mont-Joli, Quebec G5H 3Z4, Canada

${ }^{5}$ Pêches \& Océans Canada, Région du Golfe, Moncton, New Brunswick E1C 9B6, Canada

\begin{abstract}
In a previous study, a major remodeling of lipids, consistent with the theory of homeoviscous adaptation, was observed in the juvenile hard clam Mercenaria mercenaria during a temperature reduction from 24 to $-1^{\circ} \mathrm{C}$. In addition, the lipid remodeling varied between genetically distinct lines of hard clams. The present study examined whether adult hard clams originating from different locations and a selectively bred variety show differences related to their genetic characteristics in the remodeling of lipids that normally occur during decreasing temperatures. Wild hard clams from 4 locations in Atlantic Canada and the selectively bred M. mercenaria var. notata were held at an aquaculture growout site located at the northern distribution limit of the species in the Gulf of St. Lawrence from August to December 2006. Gills were sampled monthly for lipid analyses. Hard clams from the 5 groups showed an increase in the unsaturation index, mainly attributable to 22:6n-3 and 20:5n-3 as temperature decreased during the fall, followed by an increase in the phospholipid to sterol ratio in December. Although hard clams from the wild showed a lower unsaturation index than the selectively bred clams, there was no effect of location on the lipid remodeling. This result coincided with low genetic differentiation among hard clams from the 5 groups. Interestingly, the levels of $20: 5 n-3,20: 4 n-6$ and $22: 6 n-3-3$ fatty acids obtained from the diet-were generally lower in the environment compared to the levels in hard clams, thus suggesting some mechanisms for the selective incorporation of these fatty acids in hard clams.
\end{abstract}

KEY WORDS: Acclimatization · Allozymes · Bivalve $\cdot$ Fatty acid · Food - Intraspecific variation · Membrane lipid $\cdot$ Phospholipid $\cdot$ Sterol

\section{INTRODUCTION}

In poikilothermic animals, temperature changes usually induce a remodeling of the membrane lipid composition to counteract the effect of temperature on membrane order. This phenomenon is often referred to as 'homeoviscous adaptation' (HVA; Sinensky 1974, Hazel 1995, Hayward et al. 2007). Remodeling of membrane lipids usually involves changes in phospholipid head groups, acyl-chain composition and cholesterol content (Hazel \& Williams 1990). Previous studies on rainbow trout showed that exposure to low temperatures led to rapid and transient changes in phospholipid head groups and monounsaturated fatty acids (MUFA) of kidney plasma membranes, whereas polyunsaturated fatty acids (PUFA) increased gradually during cold acclimation (Hazel \& Landrey 1988a,b). In the juvenile hard clams Mercenaria mercenaria an early transient increase in the phospholipid to sterol ratio is thought to be a short-term adjustment to a 
lowering of environmental temperatures, whereas the later increase in PUFA is viewed as a long-term adjustment to winter temperature (Pernet et al. 2006).

Intraspecific variations in membrane lipid remodeling have been reported in hard clams Mercenaria mercenaria and eastern oysters Crassostrea virginica (Pernet et al. 2006, 2008). For example, the phospholipid to sterol ratio in wild hard clams increased transiently with the lowering of temperature, whereas it remained constant in the selectively bred $M$. mercenaria var. notata (Pernet et al. 2006). Therefore, the capacity for adjusting the phospholipid to sterol ratio in response to environmental temperature may have been lost during the selection for fast-growing hard clams. Alternatively, the lipid remodeling that normally occurs during a decrease in temperature may vary as a function of latitude in ectothermic animals, reflecting local adaptation to environmental temperature.

The hard clam Mercenaria mercenaria is widely distributed from the Gulf of St. Lawrence (Baie des Chaleurs, New Brunswick, Canada) to the Florida Keys (USA). At the northern distribution limit, M. mercenaria is erratically distributed in warm, shallow bays or estuaries. Adult hard clams from Canada are genetically distinct from those collected in southernmost locations in the United States (Dillon \& Manzi 1992). The distribution pattern at northern locations and the genetic population structure of hard clams along the Atlantic coast of North America together suggest that local adaptation may occur in $M$. mercenaria.

Our present investigation examines lipid remodeling in the gill of adult hard clams from different locations and varieties exposed to declining temperatures. Briefly, wild hard clams from 4 locations in Atlantic Canada and the selectively bred Mercenaria mercenaria var. notata were held at an aquaculture growout site located at the northern limit of the species' distribution in the Gulf of St. Lawrence from August to December 2006. Over the course of this study, hard clams were exposed to a gradual lowering in temperature from $\sim 23$ to $-1^{\circ} \mathrm{C}$ over $4 \mathrm{mo}$, during which gills were sampled for lipid class and fatty acid analyses. The underlying premise of the present study is that hard clams from northern locations show a much more pronounced lipid remodeling compared to that occurring in clams from southern locations, where temperatures are more stable (Fig. 1; see Bricelj et al. 2007 for temperature profiles in the Gulf of St. Lawrence). Hard clams from the 5 groups were characterized genetically to inves- tigate whether different patterns in lipid remodeling are related to their genetic characteristics.

Unlike studies that only focus on the thermal effects on membrane lipids, we also examined the dynamics of dietary lipids available in the environment. In marine bivalves, PUFA, such as 20:4n-6, 20:5n-3 and 22:6n-3, are essential for sustaining optimal growth (Langdon \& Waldock 1981, Webb \& Chu 1983 for review). The biosynthetic production of these PUFA is insufficient to satisfy the nutritional requirements of bivalves, so they are obtained pre-formed from the diet. The comparison of PUFA between clam tissues and the environment allows one to determine if the increase in the proportion of long-chain PUFA that normally occurs during a temperature decrease is an active regulatory mechanism or a reflection of changes in the clams' food.

\section{MATERIALS AND METHODS}

Hard clams. Wild hard clams Mercenaria mercenaria used in this study were collected: (1) at 3 locations at the northern limit of the species' distribution in the Gulf of St. Lawrence (Canada), namely Tabusintac $\left(\mathrm{Tb}, 47^{\circ} 27^{\prime} \mathrm{N}, 65^{\circ} 00^{\prime} \mathrm{W}\right)$ Bouctouche $\left(\mathrm{Bo}, 46^{\circ} 49^{\prime} \mathrm{N}\right.$, $64^{\circ} 67^{\prime} \mathrm{W}$ ) and Tatamagouche (Tm, 45 $\left.76^{\prime} \mathrm{N}, 63^{\circ} 35^{\prime} \mathrm{W}\right)$ (New Brunswick, Canada), and (2) at 1 location in southern Canada at St. Mary's Bay (St, 44 56' N, $65^{\circ} 85^{\prime} \mathrm{W}$ ) in the Bay of Fundy (Nova Scotia) (Fig. 1). $M$. mercenaria var. notata (Mmn) resulted from a selective breeding program to distinguish it from wild stock and to develop a more rapidly growing hard clam (Chanley

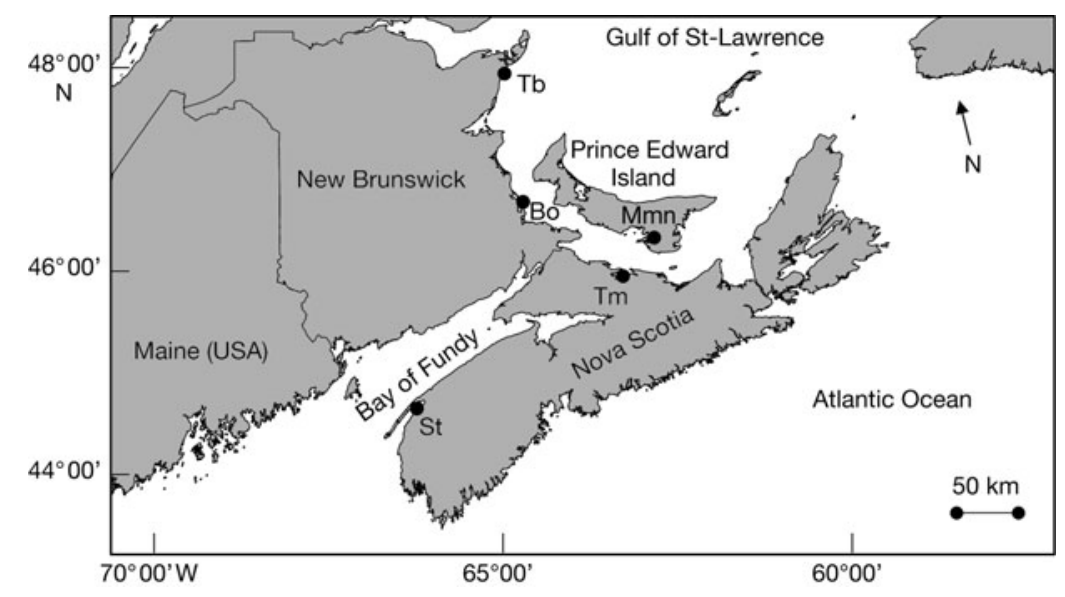

Fig. 1. Study area, eastern Canada. Adult hard clams Mercenaria mercenaria were collected at Tabusintac ( $\mathrm{Tb})$, Bouctouche (Bo) and Tatamagouche (Tm) in the Gulf of St. Lawrence and at one location in southern Canada (St. Mary's Bay, the Bay of Fundy [St]). Selectively bred hard clams $M$. mercenaria var. notata (Mmn) were initially from Ellerslie Shellfish Hatchery in Prince Edward Island and were held at an aquaculture growout site in Vernon, Prince Edward Island. The experiment was carried out at the site Bouctouche 
1961). In 1997, a sample of 60 adult hard clams from the Aquaculture Research Corporation in Dennis, Massachusetts, USA, was imported to the Ellerslie Shellfish Hatchery on Prince Edward Island (PEI, Canada). The $F_{1}$ generation was placed at growout sites to assess the performance of the variety notata in the field for $5 \mathrm{yr}$ and was then recovered to produce the $F_{2}$ generation in 2003. These clams were then maintained at an aquaculture growout site located at Vernon (PEI, Canada, 46 $12^{\prime} \mathrm{N}, 62^{\circ} 91^{\prime} \mathrm{W}$ ) for $\sim 4 \mathrm{yr}$. The notata adult clams in the present study belong to the same generation as the juveniles used in Pernet et al. (2006). In the Gulf of St. Lawrence, seawater reaches temperature as high as 23 to $26^{\circ} \mathrm{C}$ during the summer and stabilizes at $-1^{\circ} \mathrm{C}$ for 3 mo during the winter. In St. Mary's Bay, seawater temperature is only $15^{\circ} \mathrm{C}$ during the summer and varies between -1 and $+2^{\circ} \mathrm{C}$ during the winter (Bricelj et al. 2007).

Hard clams were transported to the Coastal Zone Research Institute (CZRI, Shippagan, New Brunswick, Canada), where they were held for a maximum of $2 \mathrm{wk}$ in a $630 \mathrm{l}$ tank continuously supplied with sand-filtered $(12 \mathrm{~mm})$ seawater. Clams from each location were screened for pathology and parasites by histology ( $\mathrm{n}=30$ clams per location and variety). The average shell length was $49.9 \mathrm{~mm}$, and the difference in shell length between the biggest (Tm) and the smallest $(\mathrm{Tb})$ clam was $\sim 29 \%$. The remaining clams were marked with bee tags before being placed in the field.

Experimental design. Hard clams were transferred on 10 August 2006 to Bo, the northern distribution limit of this species (Fig. 1). Twenty-five hard clams from each location and variety were placed in 15 quadrats (125 clams quadrat ${ }^{-1}$, dimensions: $0.8 \times 0.8 \times 0.2 \mathrm{~m}$ deep) at a density of 195 clams $\mathrm{m}^{-2}$. Each quadrat was buried in the upper subtidal zone and covered with predator-proof mesh (23.8 $\mathrm{mm}$ mesh size) that was held afloat with buoys. The replicated quadrats were at least $30 \mathrm{~cm}$ deep at low tides. Three clams per location and variety were sampled in 3 randomly chosen quadrats on each sampling date: 22 August, 18 September, 13 October, 11 November and 8 December 2006. Each clam was measured and carefully dissected to collect $\sim 100 \mathrm{mg}$ wet mass of gill, which was stored at $-80^{\circ} \mathrm{C}$ in lipid-free amber glass vials with Teflon-lined caps under nitrogen in $1 \mathrm{ml}$ dichloromethane for later determination of lipid composition. In addition, seston and sediments collected in each quadrat were also sampled for lipid analyses.

Environmental parameters. Seston was sampled by means of a 21 horizontal water sampler from Wildco (Buffalo, NY, USA) as previously described (Carmichael et al. 2004). The water intake was located $\sim 2 \mathrm{~cm}$ from the bottom. Each sample was filtered on a
$150 \mu \mathrm{m}$ mesh size brass sieve and then collected on Whatman GF/F filters pre-combusted at $480^{\circ} \mathrm{C}$. Filters were stored at $-80^{\circ} \mathrm{C}$ in lipid-free amber glass vials with Teflon-lined caps under nitrogen in $1 \mathrm{ml}$ dichloromethane for later determination of lipid composition. Sediments were sampled with a steel cylinder (dimensions: $3.6 \mathrm{~cm}$ diameter $\times 10.8 \mathrm{~cm}$ height), and the whole sample was stored at $-20^{\circ} \mathrm{C}$ in lipid-free amber glass vials until lipid extraction. Temperature was recorded every half hour with a 8-bit Minilog-TR data logger (Vemco) at Bouctouche from August to December 2006. The data logger was anchored at a depth of $2 \mathrm{~cm}$ into the sediment.

Genetic analysis. A small piece of muscle tissue was sampled from 60 clams from each location and variety. The samples were stored at $-80^{\circ} \mathrm{C}$ at CZRI for later electrophoretic analyses of enzymes as previously described (Tremblay et al. 1998). Briefly, $\sim 0.2 \mathrm{~g}$ of muscle was homogenized in an approximately equal volume of homogenization buffer $\left(0.2 \mathrm{~mol} \mathrm{l}^{-1}\right.$ Tris$\mathrm{HCl}, \mathrm{pH} 8.0$, with $30 \%$ sucrose, $1 \%$ polyvinylpolypyrrolidone, $0.1 \% \mathrm{NAD}, 5 \mathrm{mmol} \mathrm{l}^{-1}$ dithiothreitol and $1 \mathrm{mmol} \mathrm{l}^{-1}$ phenylmethylsulfonyl fluoride), centrifuged at $15000 \times g$ for $30 \mathrm{~min}$ at $4^{\circ} \mathrm{C}$, and the supernatant was applied to a horizontal cellulose acetate gel (Hebert $\&$ Beaton 1989). Seven allozyme loci were analyzed: phosphate glucose isomerase ( $P G I^{*}$, EC 5.3.1.9), phosphoglucomutase $\left(P G M^{*}\right.$, EC 5.4.2.2), mannose phosphate isomerase $\left(M P I^{*}, \mathrm{EC} 5.3 .1 .8\right)$, pyruvate kinase $\left(P K^{*}\right.$, EC 2.7.1.40), fumarate hydratase (FUM*, EC 4.2.1.2), isocitrate dehydrogenase ( $\left.I D H^{*}, \mathrm{EC} 1.1 .1 .42\right)$ and leucyl aminopeptidase ( $\left.L A P^{*}, \mathrm{EC} 3.4 .11 .1\right)$. Alleles were named $A, B$, etc., in order of electrophoretic mobility, such that the slowest allele was designated A. As a standard, a mixture of individuals containing all alleles present at each locus was used to identify genetic characteristics. Only 1 allele was observed at the loci $\mathrm{MPI}^{*}$, FUM* and $I D H^{*}$ (monomorphic); these loci are not considered further.

Lipid analysis. Lipids were extracted following the method of Folch et al. (1957). Sediment was sonicated in dichloromethane/methanol/water (8:4:3 v/v/v), centrifuged, and the organic layer was removed. This procedure was repeated 5 times and the organic layers were pooled (Copeman \& Parrish 2003). Once extracted, lipids were spotted onto S-III chromarods (Iatron Laboratories Inc.) and separated into aliphatic hydrocarbons, sterol and wax esters, ketones, triacylglycerols, free fatty acids, free fatty alcohol, free sterols, diacylglycerols, acetone mobile polar lipids and phospholipids (Parrish 1999). Chromarods were scanned by a flame ionization detection system (FID; Iatroscan Mark-VI, Iatron Laboratories), and chromatograms were analyzed using integration software (Peak Simple version 3.2, SRI). Fatty acid methyl 
esters (FAME) from total lipids (mainly phospholipids) were prepared using $2 \% \mathrm{H}_{2} \mathrm{SO}_{4}$ in methanol (Lepage \& Roy 1984). Gas chromatograph parameters and the procedure for FAME identification and analysis have previously been described (Pernet et al. 2007b).

Data analysis. Two different tests were used to estimate genetic differences between samples and variety. First, pairwise $F_{\text {st }}$ (Weir \& Cockerham 1984) comparisons were carried out using the software GENEPOP 4.0 (Rousset 2008). Second, allelic frequencies were compared using the exact probability test implemented in GENEPOP 4.0 (Rousset 2008). Significance levels for statistical tests were adjusted according to the sequential Bonferroni procedure (Rice 1989).

Two-way, split-plot analyses of variance (ANOVAs) were conducted to determine differences in lipid composition as a function of clam origin (location or variety) and sampling time. The unit of replication was the quadrat in which the clams from different locations and varieties were placed ( $\mathrm{n}=3$ for each sampling date). The main plots were sampling date and the sub-plots were clam origin (location or variety). Dependent variables were the phospholipid to sterol ratio, the unsaturation index and the major PUFA, namely 22:6n-3, 20:5n-3 and 20:4n-6. Here, we used general linear model repeated ANOVAs. The need for repeated measurements arose because clams from different locations and varieties were placed in the same experimental unit (quadrat). These terms were combined with the covariance structure of the matrix to take into account spatial dependence (SAS Institute 2002). One-way ANOVAs were conducted to determine differences in the fatty acid composition of the seston and the sediment as a function of time.

Where significant differences were detected, Tukey's multiple comparison test was used. Residuals were tested for normality using the Kolmogorv-Smirnov test. When necessary, data were log +1 transformed to achieve normality or homogeneity of variance. Homogeneities of variance were determined with Levene's test. Statistical analyses were carried out using SAS 9.1.3 (SAS Institute).

\section{RESULTS}

\section{Temperature measurements}

Seawater temperature decreased from 23 to $-1^{\circ} \mathrm{C}$ over the study period (Fig. 2). Overall, clams experienced a decrease in temperature of $\sim 0.2^{\circ} \mathrm{C} \mathrm{d}^{-1}$. However, a marked increase in daily temperature from 3 to $11^{\circ} \mathrm{C}$ occurred between 8 and 18 November.

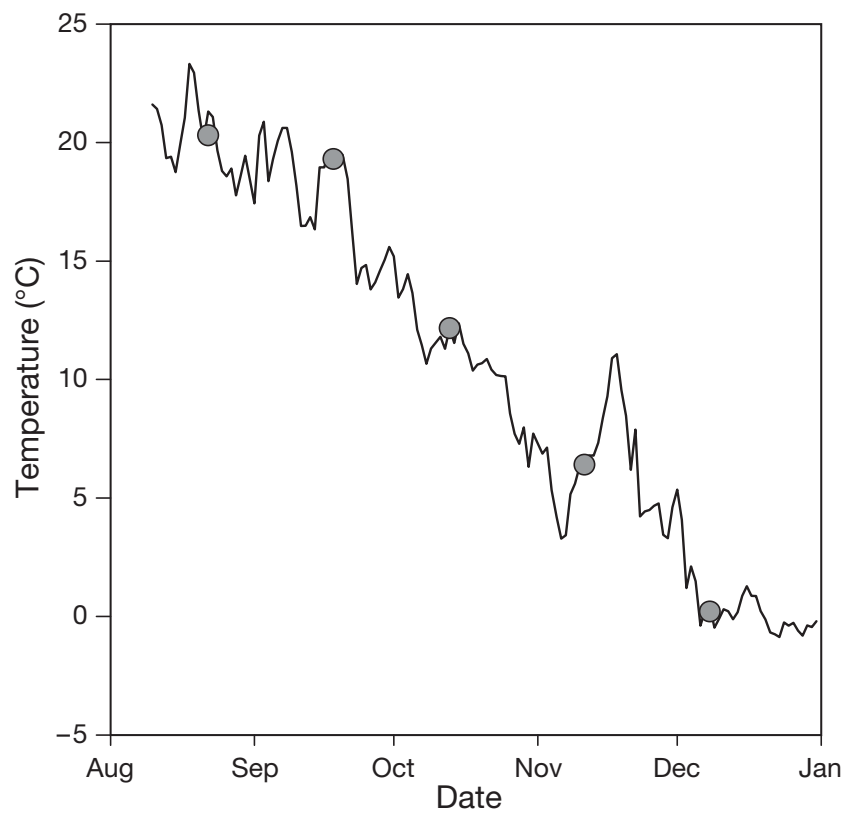

Fig. 2. Temperature monitoring in the field at Bouctouche (New Brunswick, Canada) from 11 August to 31 December 2006. Circles: dates when clam tissues, seston and sediment were sampled for lipid analysis

\section{Genetic characterization}

The genetic characteristics of each sample (e.g. allelic frequencies, observed and expected heterozygosities, conformance to Hardy-Weinberg equilibrium) are presented in Parent (2008). The overall $F_{\text {st }}$ value among locations and varieties of clams Mercenaria mercenaria was $0.011(\mathrm{p}<0.001)$, which indicates genetic differentiation among groups. Pairwise significant differences were detected between clams from Bo and and the Mmn stock $\left(F_{\mathrm{st}}=0.044, \mathrm{p}=0.002\right)$ and Bo and St $\left(F_{\mathrm{st}}=0.033, \mathrm{p}=0.002 ;\right.$ Table 1$)$. Hard clams from Bo and Mmn stock showed significant differences in their allelic frequencies for $P K^{*}$ and $L A P^{*}$ (Fisher exact test for each of these 2 loci, $\mathrm{p}<0.001$ ). Also, clams from Bo and St showed significant differences in their allelic frequencies for $L A P^{*}(\mathrm{p}=0.004)$.

Table 1. Mercenaria mercenaria. Matrix of an index of genetic differentiation among 5 groups of hard clams. For site abbreviations see Fig. 1. Above the diagonal are p-values, below the diagonal are $F_{\text {st }}$ (Wright's fixation index). NS: not significant; bold: significant

\begin{tabular}{|lccccc|}
\hline & \multicolumn{6}{c|}{ Variety/Location } & & \\
\cline { 3 - 6 } & Mmn & St & Tm & Bo & Tb \\
\hline Mmn & - & NS & NS & $\mathbf{0 . 0 0 2}$ & NS \\
St & 0.000 & - & NS & $\mathbf{0 . 0 0 2}$ & NS \\
Tm & 0.000 & 0.000 & - & 0.007 & NS \\
Bo & 0.044 & 0.033 & 0.031 & - & 0.037 \\
Tb & 0.000 & 0.000 & 0.000 & 0.017 & - \\
\hline
\end{tabular}




\section{Lipid classes}

Lipid classes detected in gills of hard clams in the present study were sterols, acetone-mobile polar lipids and phospholipids. Minor amounts of triglycerides $(2.8 \%)$ were occasionally detected and are not discussed further. Acetone-mobile polar lipids, a lipid class that includes photosynthetic pigments, glycolipids and monoacylglycerols, showed no consistent pattern over time in clams from each location or variety (data not shown). Time and variety showed interactions in their effect on the phospholipid to sterol ratio, a variable generally considered as an indicator of membrane fluidity (Fig. 3). In August, the phospholipid to sterol ratios of hard clams originating from the northern locations, $\mathrm{Tb}$ and Bo, were respectively 2.5 and 1.8 times higher than those from southern locations (Tm and St) and the variety notata (all pairwise comparisons, p < 0.001). In December, the phospholipid to sterol ratio of clams increased significantly for Bo $(p=0.001)$, Tm $(p=0.040)$, St $(p=0.002)$ and Mmn $(p=0.002)$ compared to levels recorded in November (Fig. 3).

\section{Fatty acids}

Major fatty acids separated from the total lipid extracts of gills were 16:0 (17.6\%), 22:6n-3 (16.5\%), 22:2 non-methylene interrupted fatty acids $(8.5 \%)$, 20:5n-3 (7.1\%), 20:4n-6 (5.7\%) and 18:0 (4.9\%), which together accounted for $60 \%$ of the total fatty acids. The

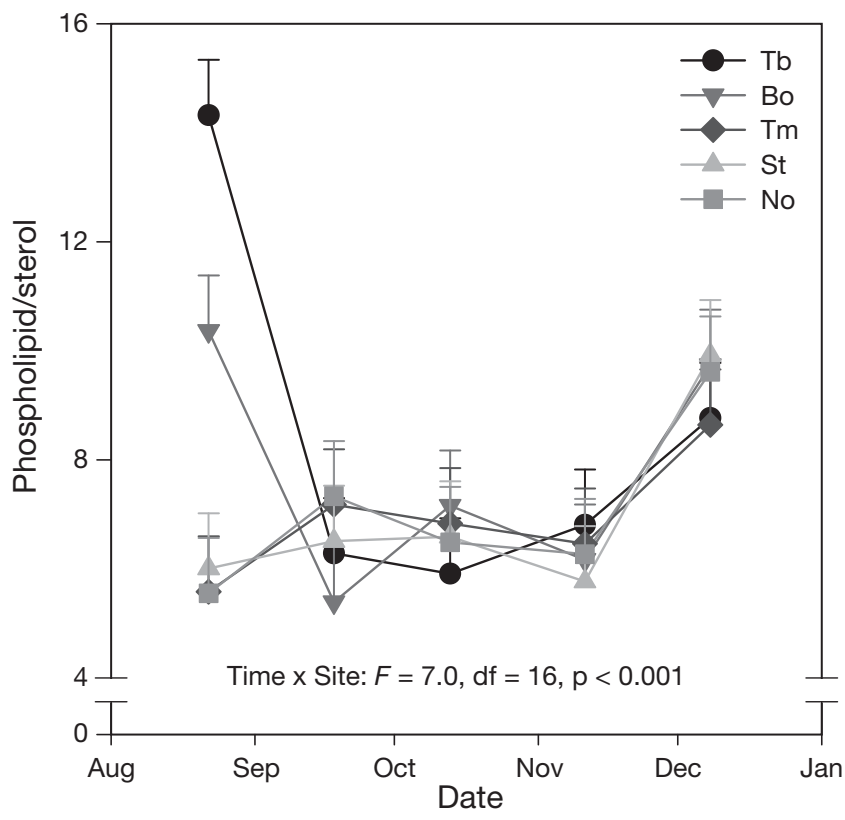

Fig. 3. Mercenaria mercenaria. Phospholipid to sterol ratio in gill tissues of clams as a function of time and origin of clams $($ mean $\pm \mathrm{SE}, \mathrm{n}=3$ ). For site abbreviations see Fig. 1 unsaturation index, which is the number of double bonds per 100 acyl chains, increased significantly for hard clams by $8.8 \%$ from September to November, when the temperature decreased from $\sim 16$ to $3^{\circ} \mathrm{C}$, and remained constant thereafter. The unsaturation index was generally lower in wild hard clams compared to that of the selectively bred hard clams, irrespective of sampling time (Fig. 4A). Variations in the unsaturation index were mainly attributable to changes in PUFA, which also varied as a function of time and variety of clam (Fig. 4B). Individual PUFAs varied as a function of location and variety; there was no consistent pattern during the entire study period for 20:4n-6, which remained constant at $\sim 5.5 \%$ (Fig. 4 C), whereas $20: 5 n-3$ and 22:6n-3 increased from August to October and November, when these 2 fatty acids attained their respective plateaus (Fig. 4D, E). The selectively bred hard clams showed higher levels of 20:4n-6 and 20:5n-3 than wild clams (Fig. 4C, D), whereas 22:6n-3 showed a trend for increasing values in hard clams from northern to southern locations (Fig. 4E).

The major fatty acids detected in the seston differed from those of hard clams, with the following percentages: $16: 0(18.3 \%), 16: 1 n-7 \quad(10.9 \%), 20: 5 n-3$ (8.6\%) and $18: 4 n-3(5.6 \%)$; the sediments were characterized by $16: 1 \mathrm{n}-7(25.4 \%), 16: 0(20.1 \%), 14: 0$ (5.8\%) and $18: 1 \mathrm{n}-7(5.1 \%)$. The unsaturation index and the level of PUFA in hard clams were higher than those of the seston and the sediment (Fig. 4A,B), and these differences were mainly attributable to $20: 4 n-6$ and $22: 6 n-3$ (Fig. 4C,E). In contrast, levels of 20:5n-3 in hard clams were rather similar to that of the seston (Fig. 4D). The unsaturation index and the level of PUFA in the seston and the sediment showed only minor changes during the entire study period. It is noteworthy that the sediment showed a very low level of $22: 6 \mathrm{n}-3(<2 \%)$ compared to that occurring in the seston, where $22: 6 n-3$ varied between 3.5 and $5.5 \%$ as a function of time.

\section{DISCUSSION}

The phospholipid to sterol ratio in hard clams Mercenaria mercenaria from northern locations ( $\mathrm{Tb}$ and $\mathrm{Bo}$ ) was initially higher than that of hard clams from southern locations (Tm and St) and the variety notata. Cholesterol affects the physical properties of membranes including their fluidity, phase behavior, thickness and permeability (Crockett 1998). Some positive correlations between membrane cholesterol content, as determined by the cholesterol to phospholipid ratio, and acclimation temperature have been reported in several tissues of rainbow trout (Robertson \& Hazel 1995). A widely accepted notion is that cholesterol stabilizes membranes, i.e. it increases the order of the surround- 
Clams
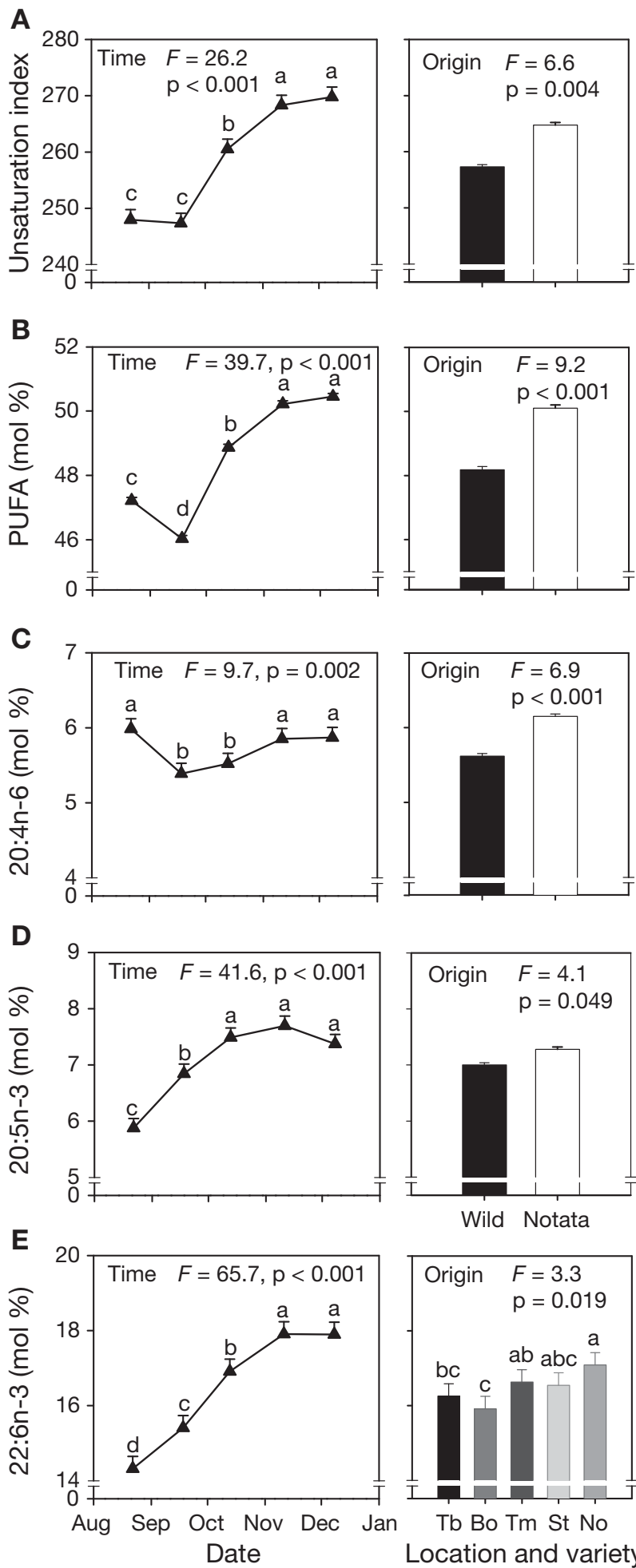

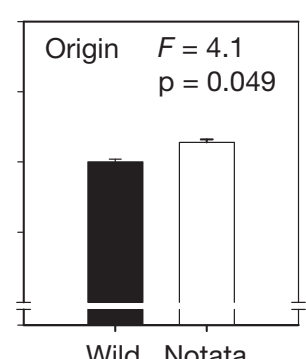

Wild Notata

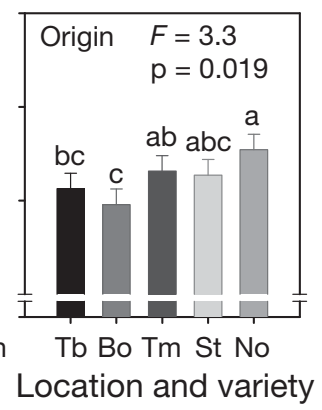

Environment
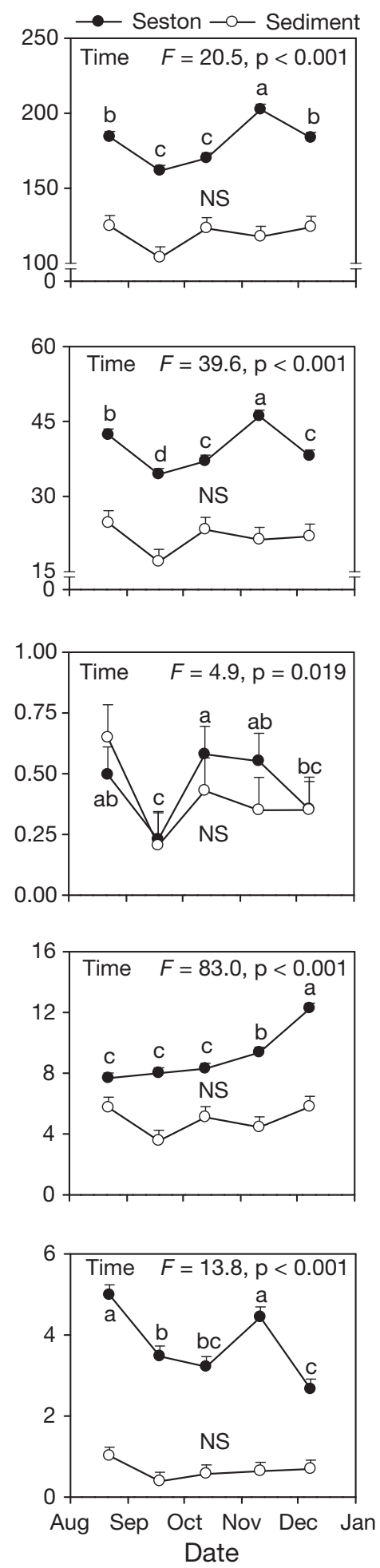

Fig. 4. Mercenaria mercenaria. Unsaturation index (A) and mol\% of polyunsaturated fatty acids (PUFA; B), arachidonic acid $(20: 4 n-6 ; C)$, eicosapentaenoic acid $(20: 5 n-3 ; D)$ and docosahexaenoic acid $(22: 6 n-3 ;$ E) in gill tissues of hard clams as a function of time and origin of clams (left and center panels) and in the environment (seston and sediment; right panels). The unsaturation index is calculated as the sum of the mol\% of each unsaturated fatty acid multiplied by the number of double bonds within that fatty acid. Data from different locations and varieties or sampling time were pooled together when the effect was not significant (mean $\pm \mathrm{SE}, \mathrm{n}=3$ ). Different letters indicate significant differences. For site abbreviations see Fig. 1. NS: not significant 
ing acyl chains in membranes in the fluid phase (Crockett 1998). Although membrane fluidity was not measured, the higher phospholipid to sterol ratio in M. mercenaria from northern locations compared to that of clams from southern locations at the onset of the experiment suggests a specific role for sterols in the membrane's homeoviscous response as a function of location and variety.

In contrast to our previous work on juvenile hard clams, where we observed a transient increase in the phospholipid to sterol ratio concomitantly with a lowering of temperature between August and October, likely as a short-term adjustment to a lowering of environmental temperatures (Pernet et al. 2006), the phospholipid to sterol ratio remained constant in adults exposed to a similar decrease in temperature. Here, we hypothesize that the transient increase in the phospholipid to sterol ratio in response to environmental temperature was typical of juveniles. It has been suggested that the use of cholesterol as a modulator may not require any expenditure of ATP or reduced cofactors (Crockett 1998). Therefore, modulation of the phospholipid to sterol ratio probably provides a metabolically less expensive mechanism of membrane remodeling than de novo synthesis of PUFA-rich phospholipids. Although speculative, regulation of the phospholipid to sterol ratio may represent an alternative to the selective incorporation of essential PUFA in small juveniles for which aerobic energy expenditures on a weight-specific basis are generally higher than those of adults (Koehn 1989).

In contrast, the phospholipid to sterol ratio increased between November and December, while the temperature decreased from 6 to $0^{\circ} \mathrm{C}$, which is consistent with a role for cholesterol in the membrane's homeoviscous response. Given that modulation of the phospholipid to sterol ratio requires less energy than does the modification of fatty acid composition, this mechanism may be viewed as a way of saving energy. It is noteworthy that hard clams were characterized by low levels of storage triglyceride in their digestive gland $(<5 \%$ of total lipids; authors' unpubl. data), thus suggesting that the energy reserves in these clams were low.

The unsaturation index in hard clam gills increased from September to November as the seawater temperature decreased from 21 to $6^{\circ} \mathrm{C}$, irrespective of location or variety, as previously reported for the soft tissues of juveniles (Pernet et al. 2006). The increase in the unsaturation index is attributable to changes in PUFA and, more particularly, to changes in 22:6n-3 and 20:5n-3. Although we did not measure membrane fluidity, these alterations in membrane lipid composition during cold acclimatization were consistent with membrane HVA. In several bivalve species, 22:6n-3 and 20:5n-3 are negatively correlated with environmental temperature (Hall et al. 2002, Pernet et al. 2006, 2007a,b, 2008).

The unsaturation index and main PUFA were lower in wild hard clams from Canada compared to those of the selectively bred Mercenaria mercenaria var. notata, which originates from Massachusetts (USA), as previously observed in juveniles (Pernet et al. 2006). In this previous work, the lower unsaturation index in wild hard clams coincided with lower metabolic requirements, as predicted by Hulbert's theory of membranes as pacemakers of metabolism (Hulbert \& Else 1999). It is therefore likely that differences in metabolic requirements between strains of hard clam persist in adults. Differences in the unsaturation index and fatty acid composition between wild and selectively bred hard clams may reflect a biogeographic pattern, the selection for fast-growing clams, or both, as these 2 variables were confounded. It is noteworthy that there was no alteration in the lipid fatty acid composition in hard clams from the different locations tested in this study.

Interestingly, the unsaturation index and levels of long-chain PUFA in hard clam gills were markedly higher than those observed in both the seston and the sediment. Furthermore, the unsaturation index in gills increased markedly with a lowering in temperature, whereas it remained constant in the sediment and changed only slightly in the seston. Although certain long-chain PUFA, such as 20:4n-6, 20:5n-3 and 22:6n-3, are essential in bivalves and need to be obtained from the diet, these results suggest that the fatty acid composition of membrane lipids in bivalves is strongly regulated. Selective incorporation or elimination of certain fatty acids likely occurs in membrane lipids in bivalves, as has been previously suggested in other studies (e.g. Delaunay et al. 1993, Soudant et al. 1998, Pernet et al. 2005, 2008). This suggests that the increase in long-chain PUFA in clams that occurs during a temperature decrease is an active regulatory mechanism that remains somewhat independent of the food.

In conclusion, the present study confirms previous findings: hard clams, like other bivalve species, change their lipid composition in a direction consistent with HVA when environmental temperatures decrease. In addition, the unsaturation index in wild hard clams was lower than that of the selectively bred variety, as previously observed in juvenile hard clams (Pernet et al. 2006). Therefore, differences in the unsaturation index between strains of hard clams persisted in adults. For the first time, this study shows that the increase in long-chain PUFA in clams that occurs during a temperature decrease is an active regulatory mechanism that remains somewhat independent of available food. Finally, hard clams collected from dif- 
ferent sites in Atlantic Canada did not show the consistent differences in the remodeling of lipids that normally occur during a decrease in temperature; this coincides with the low genetic differentiation index among clams from the 4 selected locations. The latitudinal gradient used in the present study was likely not large enough to detect major genotypic and phenotypic differences.

Acknowledgements. The authors are grateful to Catherine Gaudreau (ISMER/UQAR), Aurélie Licois (IRZC), Angelica LeBlanc and Jean-François Mallet (DFO) for their excellent technical assistance in the field. Thanks are also addressed to Eve-Julie Arsenault (IRZC) for her help throughout the experiment, Josée Duguay and Claude Pelletier (IRZC) for their assistance with lipid analysis, and Sonia Belvin (ISMER/ MAPAQ) for histopathology. Finally, the authors also thank Alain Caron (UQAR/ISMER) for statistical analyses and Laure Devine (DFO) for revising the English version of this manuscript. This study was supported by an NSERC Discovery Grant and an AIF grant to F.P. This research is part of an MS dissertation by G. Parent at the Université du Québec à Rimouski, Institut des Sciences de la Mer.

\section{LITERATURE CITED}

Bricelj MV, Ouellette C, Anderson M, Brun NT, Pernet F, Ross NW, Landry T (2007) Physiological and biochemical responses of juvenile quahogs, Mercenaria mercenaria, to low temperatures: potential for mitigation of overwintering mortalities. Can Tech Rep Fish Aquat Sci 2739

Carmichael RH, Shriver AC, Valiela I (2004) Changes in shell and soft tissue growth, tissue composition, and survival of quahogs, Mercenaria mercenaria, and softshell clams, Mya arenaria, in response to eutrophic-driven changes in food supply and habitat. J Exp Mar Biol Ecol 313:75-104

Chanley PE (1961) Inheritance of shell markings and growth in the hard clam, Venus mercenaria. Proc Natl Shellfish Assoc 50:163-169

Copeman LA, Parrish CC (2003) Marine lipids in a cold coastal ecosystem: Gilbert Bay, Labrador. Mar Biol 143: 1213-1227

Crockett EL (1998) Cholesterol function in plasma membranes from ectotherms: membrane-specific roles in adaptation to temperature. Am Zool 38:291-304

> Delaunay F, Marty Y, Moal J, Samain JF (1993) The effect of monospecific algal diets on growth and fatty acid composition of Pecten maximus (L.) larvae. J Exp Mar Biol Ecol 173:163-179

Dillon RT, Manzi JJ (1992) Population genetics of the hard clam, Mercenaria mercenaria, at the northern limit of its range. Can J Fish Aquat Sci 49:2574-2578

Folch J, Lees M, Sloane-Stanlez GH (1957) A simple method for the isolation and purification of total lipids from animal tissues. J Biol Chem 226:497-509

Hall JM, Parrish CC, Thompson RJ (2002) Eicosapentaenoic acid regulates scallop (Placopecten magellanicus) membrane fluidity in response to cold. Biol Bull 202: 201-203

Hayward SAL, Murray PA, Gracey AY, Cossins AR (2007) Beyond the lipid hypothesis: mechanisms underlying phenotypic plasticity in inducible cold tolerance. In: Csermely $\mathrm{P}$, Vígh L (eds) Molecular aspects of the stress response: chaperones, membranes and networks, Vol 594. Springer, New York, p 132-142

Hazel JR (1995) Thermal adaptation in biological membranes: Is homeoviscous adaptation the explanation? Annu Rev Physiol 57:19-42

Hazel JR, Landrey SR (1988a) Time course of thermal adaptation in plasma membranes of trout kidney. I. Headgroup composition. Am J Physiol Regul Integr Comp Physiol 255:R622-R627

Hazel JR, Landrey SR (1988b) Time course of thermal adaptation in plasma membranes of trout kidney. II. Molecular species composition. Am J Physiol Regul Integr Comp Physiol 255:R628-R634

> Hazel JR, Williams EE (1990) The role of alterations in membrane lipid composition in enabling physiological adaptation of organisms to their physical environment. Prog Lipid Res 29:167-227

Hebert PDN, Beaton MJ (1989) Methodologies for allozyme analysis using cellulose acetate electrophoresis: a practical handbook. Helena Laboratories, Beaumont, TX

- Hulbert AJ, Else PL (1999) Membranes as possible pacemakers of metabolism. J Theor Biol 199:257-274

Koehn RK (1989) Towards a physiological and genetical understanding of the energetics of the stress response. Biol J Linn Soc 37:157-171

Langdon CJ, Waldock MJ (1981) The effect of algal and artificial diets on the growth and fatty acid composition of Crassostrea gigas spat. J Mar Biol Assoc UK 61:431-448

> Lepage G, Roy CC (1984) Improved recovery of fatty acid through direct transesterification without prior extraction or purification. J Lipid Res 25:1391-1396

Parent GJ (2008) Acclimatation thermique de la palourde américaine, Mercenaria mercenaria: expérimentation en jardin commun. MSc dissertation, Université du Québec à Rimouski

Parrish CC (1999) Determination of total lipid, lipid classes, and fatty acids in aquatic samples. In: Arts MT, Wainman BC (eds) Lipids in freshwater ecosystems. SpringerVerlag, New York, p 5-20

Pernet F, Bricelj VM, Parrish CC (2005) Effect of varying dietary levels of w6 polyunsaturated fatty acids during the early ontogeny of the sea scallop, Placopecten magellanicus. J Exp Mar Biol Ecol 327:115-133

Pernet F, Tremblay R, Gionet C, Landry T (2006) Lipid remodeling in wild and selectively bred hard clams at low temperatures in relation to genetic and physiological parameters. J Exp Biol 209:4663-4675

$>$ Pernet F, Gauthier-Clerc S, Mayrand E (2007a) Change in lipid composition in eastern oyster (Crassostrea virginica Gmelin) exposed to constant or fluctuating temperature regimes. Comp Biochem Physiol B Biochem Mol Biol 147: $557-565$

> Pernet F, Tremblay R, Comeau L, Guderley H (2007b) Temperature adaptation in two bivalve species from different thermal habitat: energetic and remodeling of membrane lipids. J Exp Biol 210:2999-3014

Pernet F, Tremblay R, Redjah I, Sevigny JM, Gionet C (2008) Physiological and biochemical traits correlate with differences in growth rate and temperature adaptation among groups of the eastern oyster Crassostrea virginica. J Exp Biol 211:969-977

> Rice WR (1989) Analysing tables of statistical tests. Evolution 43:223-225

Robertson JC, Hazel JR (1995) Cholesterol content of trout plasma membranes varies with acclimation temperature. Am J Physiol 38:R1113-R1119

Rousset F (2008) GENEPOP'007: a complete re-implementa- 
tion of the GENEPOP software for Windows and Linux. Mol Ecol Notes 8:103-106

SAS Institute (2002) SAS 9.1.3 help and documentation. SAS Institute, Cary, NC

Sinensky M (1974) Homeoviscous adaptation - a homeostatic process that regulates the viscosity of membrane lipids in Escherichia coli. Proc Natl Acad Sci USA 71:522-525

Soudant P, Marty Y, Moal J, Masski H, Samain JF (1998) Fatty acid composition of polar lipid classes during larval development of scallop Pecten maximus (L.). Comp Biochem Physiol Physiol 121:279-288

Editorial responsibility: Judith Grassle,

New Brunswick, New Jersey, USA
Tremblay R, Myrand B, Sevigny JM, Blier P, Guderley H (1998) Bioenergetic and genetic parameters in relation to susceptibility of blue mussels, Mytilus edulis (L.) to summer mortality. J Exp Mar Biol Ecol 221:27-58

Webb KL, Chu FLE (1983) Phytoplankton as food source for bivalve larvae. In: Pruder GD, Langdon CJ, Conklin DE (eds) Proc 2nd Int Conf on aquaculture nutrition: biochemical and physiological approaches to shellfish nutrition. Louisiana State University, Baton Rouge, p 272-291

Weir BS, Cockerham CC (1984) Estimating F-statistics for the analysis of population structure. Evolution 38:1358-1370

Submitted: March 17, 2008; Accepted: June 11, 2008

Proofs received from author(s): July 10, 2008 